21

\section{HELICOBACTER PYLORI (HP) INFECTION RISK IN NEWBORN FROM HP POSITIVE MOTHERS.}

ME BALDASSARRE ${ }^{l}$, F. INDRIO ${ }^{l}$, R. MONNO ${ }^{2}$, M. FANELLI $I^{3}$, M. QUERCIA ${ }^{l}$, F.G. RUSSO ${ }^{l}$, A MAUTONE ${ }^{I}, N$. LAFORGIA ${ }^{l}{ }^{l}$ DEPARTEMENT OF PEDIATRICS NEONATOLOGY SECTION UNI VERSITY OF BARI, ${ }^{2}$ DEPARTMENT OF MICROBIOLOGY UNIVERSITY OF BARI, ${ }^{3}$ DEPARTMEN OF INTERNAL MEDICIN AND PUBLIC HEALTH MEDICAL STATISTICS UNIVERSITY OF BARI (ITALY)

Experimental data on long term helicobacter pylori (HP) infection indicate that inflammation can develop in gastric mucosa after infection so that it could be very important the prevention of neonatal and childhood gastric mucosa after infection so that it could be very important the prevention of neonatal and childhood
infection. Few reports have been published concerning horizontal and vertical transmission of HP infection infection.

We investigated newborns from HP positive mothers to evaluate HP infection transmission. From June 2002 to December 2004 we evaluated 165 pairs mother-newborn. Mothers: serological test for HP antibodies (HPab; Helicobacter pylori IgG Elisa, Eurospital, Italy) and stool antigen testing (Helori, Eurospital, Italy); urea Breath test (UBT) was performed only in positive cases.

Newborns: stool antigen testing (Helori, Eurospital) in the first month of life and every six months until EIA,Radim, Italy) at three months. Statistical analysis: chi-square test.

Preliminary results.

Mothers: 62/165( $37.5 \%$ ) were both serological and stool-antigen testing positive. UBT in 57/62 (92\%) resulted positive in $52 / 57(91.2 \%$ ). 649 stool samples of newborns have been analyzed: $3 / 52(5.7 \%)$ resulted positive in first month of life (HPab against CAG-A all positive): one became negative at one year and two cases were still positive at eighteen months.

No newborns of negative mothers had a positive antigen stool testing, with a statistical difference compared to newborns from positive mothers $(\mathrm{p}<0.05)$. Conclusion. HP infection could be acquired in neonatal age from HP positive mothers. Stool antigen testing represents an easy and non-invasive method for the diagnosis of infection in newborns.

References.

J Epidemiol 2000; 11:7

JPGN 1994; 19: 87

Eur J Clin Microbiol Infect Dis 1995; 14: 727

\section{2}

BREASTFEEDING ACROSS GEOGRAPHICAL AREAS IN ITALY

M. GIOVANNINI ${ }^{l}$, E. RIVA ${ }^{l}$, G. BANDERALI ${ }^{l}$, I. BRUNETTI ${ }^{l}$, G. RADAELLII ${ }^{1}$, C. AGOSTONI IDEPARTMENT OF PEDIATRICS, SAN PAOLO HOSPITAL, UNIVERSITY OF MILAN (ITALY)

Objective. To evaluate and compare the rates of initiation and duration of breastfeeding across geographical areas of Italy.

Methods. A total of 2450 mothers, who delivered a healthy full term infant in Italy, were interviewed through the first 12 months after delivery about feeding practices. Breastfeeding was classified in accordance with the World Health Organization (WHO). Adherence to the WHO ten steps to successful breastfeeding was further assessed. Chi-square and log-rank tests, logistic and Cox regressions were used for the statistical analysis.

Results. Breastfeeding started in $91 \%$ of mothers, ranging from $85 \%$ (Sicilia) to $93 \%$ (North-east, South). At discharge the rate of exclusive breastfeeding was $77 \%$, ranging from $57 \%$ (Sicilia) to $81 \%$ (North-east, Sardinia). Mean duration of breastfeeding ranged from 3.1 (Sicilia) to 6.0 months (Sardinia). Mean duration of exclusive breastfeeding ranged from 1.8 (Sicilia) to 2.6 months (Northeast and Sardinia). Lower adherence to the WHO steps and less favorable socio-demographic characteristics, especially maternal lower education level, smoking habits and overweight, influenced negatively both breastfeeding and exclusive breastfeeding.

Conclusion. Differences in duration of breastfeeding and exclusive breastfeeding across geographical areas of Italy require planning of strategies for improvement, possibly taking into account for the eighteen months or three years in positive cases, in which we evaluated HPab against CAG-A (Cag-A IgG WHO steps and socio-demographic characteristics.

24

HOSPITAL VOLUME AND MORTALITY IN PRETERM NEWBORNS

D.B. BARTELS ${ }^{l}$, D WYPIJ ${ }^{2}$, P WENZLAFF ${ }^{3}$, O DAMMANN ${ }^{1,4}$, CF POETS ${ }^{5}$ DEPARTMENTS OF OBSTETRICS AND PEDIATRICS, PERINATAL INFECTIOUS DISEASE EPIDEMIOLOGY UNIT HANNOVER MEDICAL SCHOOL (GERMANY), ${ }^{2}$ CHILDREN'S HOSPITAL AND HARVARD SCHOOL OF PUBLIC HEALTH (USA), ${ }^{3}$ CENTER FOR QUALITY AND MANAGEMENT IN HEALTH CARE (GERMANY), ${ }^{4}$ NEUROEPIDEMIOLOGY UNIT, DEPTS. OF NEUROLOGY, CHILDREN'S HOSPITAL AND HARVARD MEDICAL SCHOOL (USA), ${ }^{5}$ DEPARTMENT OF NEONATOLOGY, UNIVERSITY TÜBINGEN (GERMANY)

Background: Very low birthweight infants (VLBW, $<1500 \mathrm{~g}$ ) are at increased mortality risk Neonatal intensive care (NICU) and delivery units are often detached. Previous mortality risk assessments focused on neonatal transfers as a potentially harmful exposure. Data on the impact of NICU volume are sparse.

Objective: To assess the impact of annual VLBW-infant census on 28-day-survival. We hypothesized that neonatal mortality is higher in small NICUs ( $<36$ VLBW admission/year) than in large NICUs, and that NICU volume has a larger impact than volume of the delivery unit ( $<=$ vs. $>1000$ births/year).

Methods: We analyzed population-based data from a quality assurance program in Lower Saxony (Germany). Pre-, peri- and neonatal data from almost all VLBW-infants born 1991-99 $(\mathrm{n}=7737)$ were available. Analyses were restricted to infants born at $24-30 \mathrm{wk}(\mathrm{n}=4379)$. Data validation procedures, univariable data analyses, logistic regression, and general estimating equation models were performed, the latter to appreciate data clustering within NICUs.

Results: Neonatal mortality among infants admitted to NICU was $12.2 \%$ in small and $10.2 \%$ in large NICUs. Infants from small NICUs had a significantly increased mortality rate (adjusted odds ratio 1.79 , 95\% CI 1.21-2.63). Compared to infants from large delivery units and large NICUs, the adjusted OR was $1.94(1.20-3.14)$ for newborns from both units being small, $1.75(1.10-2.78)$ for those from large delivery but small neonatal units, and $1.16(0.82-1.63)$, if the NICU was large, but not the delivery unit. Stratification by gestational age revealed the greatest impact on mortality for infants $<29 \mathrm{wk}$.

Conclusion: Our results suggest that creating larger perinatal centers might further improve perinatal health care. Volume of the NICU was more strongly associated with 28-day-mortality than that of the delivery unit, and had the largest impact on survival for infants $<29 \mathrm{wk}$.

\section{5}

ANTITHROMBIN FOR THE TREATMENT OF RESPIRATORY DISTRESS SYNDROME: A SYSTEMATIC REVIEW

D BASSLER ${ }^{l}$, D MILLAR ${ }^{l}$, B SCHMIDT ${ }^{1,2}{ }^{l}$ DEPARTMENT OF PAEDIATRICS, MCMASTER UNIVERSITY, ${ }^{2}$ DEPARTMENT OF CLINICAL EPIDEMIOLOGY AND BIOSTATISTICS, MCMASTER UNIVERSITY (CANADA)

BACKGROUND Acquired Antithrombin (AT) deficiency is a common and prognostically important finding in sick preterm infants with respiratory distress syndrome (RDS). It has been hypothesised that AT concentrate may improve clinical outcomes in preterm infants with RDS. We examined whether the administration of AT concentrate decreased mortality in preterm infants compared with placebo or no treatment.

METHODS We did a systematic review of trials that compared any dose and duration of AT therapy with placebo or no treatment in preterm infants with RDS. We used the methods of the Cochrane Collaboration. We combined data for similar outcomes where appropriate, using a fixedeffects model.

FINDINGS 2 trials consisting of 182 preterm infants, fulfilled the inclusion criteria. Mean gestational age of patients included was 28 weeks. In one trial patients had to be endotracheally intubated and ventilated for RDS to be eligible for the study. In the other trial RDS was not mentioned as an inclusion criteria, however $93 \%$ of infants in the control group received surfactant. No individual trial showed a significant difference in mortality, however one of the trials was stopped early because of an observed inbalance in deaths between the treatment groups. The pooled analysis for mortality within the first week of life showed a relative risk of 1.6 (95\% CI 0.54-4.72) in favour of the control group. Only the trial that was stopped early followed the infants long enough to report neonatal mortality. This trial reported 7 deaths $(11.5 \%)$ in the AT group and 2 deaths (3.3\%) in the placebo group within 28 days of life. Secondary outcomes included days of mechanical ventilation and supplemental oxygen which were only reported in 1 trial. Both outcomes were in favour of the control group (statistical significant).

INTERPRETATION Preterm infants with RDS do not benefit from AT treatment and may be harmed.

\section{3}

DO ADOLESCENT PREGNANCIES TEND TO REPEAT ACROSS GENERATIONS?

A BARBOSA ${ }^{l}, V$ CARDOSO ${ }^{l}$, M BARBIERI $^{l}$, H BETTIOL $^{l}$, A SILVA ${ }^{2}{ }^{l}$ FACULTY OF MEDICINE OF RIBEIRAO PRETO, UNIVERSITY OF SAO PAULO, ${ }^{2}$ DEPARTMENT OF PUBLIC HEALTH, FED ERAL UNIVERSITY OF MARANHAO (ITALY)

Background: adolescent pregnancy is highly prevalent in developing countries. It is associated with poverty, induced abortion, low maternal schooling, and maternal and infant mortality. Objective: to verify whether women born to adolescent mothers are also prone to become adolescent mothers and verify whether women born to adolescent mothers are also prone to become
to what extent this association is due to shared socioeconomic circumstances.

to what extent this association is due to shared socioeconomic circumstances.
Methods: questionnaires were applied to women who gave birth to a singleton female liveborn in 1978/79 in Ribeirao Preto, Brazil (first generation mothers). Their daughters were interviewed in 2002/04 (second generation mothers). The questions comprised information on first generation mothe variables (age at first delivery - adolescent or not - and family income) and second generation mothe variables (schooling level, childhood work and age at menarche). The association between first generation mother's age at first delivery and second generation mother's adolescent pregnancy (yes, compared to older mothers plus women who were not yet mothers) was assessed by means of univariable and multivariable Poisson regression models. The other variables listed above were considered as confounders.

Results: 1059 first and second generation woman pairs were interviewed. 181 second generation mothers also gave birth to a child while being an adolescent. If a first generation mother was an adolescent at her first delivery, her daughter presented a relative risk (RR) of being also an adolescent mother of 2.10 (95\% Confidence Interval 1.58, 2.82). After adjustment, the association was no longer observed, whilst low first generation mother's family income $(\mathrm{p}=0.003)$, second generation mother's low schooling level $(\mathrm{p}<0.001)$ and low age at menarche $(\mathrm{p}=0.032)$ were associated with adolescent pregnancy among second generation mothers.

Conclusions: women born to adolescent mothers are more prone to become adolescent mothers Repeated teenage pregnancies across generations seem to be related to social circumstances shared by both mothers and daughters.

Supported by CNPq and FAPESP.
26

COMPARATIVE EFFECTS OF IBUPROFEN (IB) AND INDOMETHACIN (IN) FOR SUPPRESSION OF RETINAL VEGF SIGNALING IN RATS KD BEHARRY ${ }^{l}, J$ HASAN ${ }^{1,2}, J V$ ARANDA ${ }^{3}$, HD MODANLOU ${ }^{1}{ }^{l}$ UNIVERSITY OF CALIFORNIA, IRVINE , ${ }^{2}$ MILLER CHILDREN'S HOSPITAL, ${ }^{3}$ CHILDREN'S HOSPITAL OF MICHIGAN (USA) action with VEGFR1 and VEGFR2. Neuropilin (Npn) has been shown to enhance VEGF164 affinity for VEGFR2. Pigment epithelium-derived factor (PEDF) is an angiogenic antagonist that is upregulated after retinal vascularization is complete. IB and IN have been shown to improve oxygen-induced retinopathy in mice. We hypothesized that IB is more effective than IN for suppression of retinal VEGF signaling in rats.

Methods: Newborn rats ( $\mathrm{n}=3$ litters/groups; 15 pups/litter) received IP injections of either saline (Sal), IB $(10 \mathrm{mg} / \mathrm{Kg}), \mathrm{IB}(50 \mathrm{mg} / \mathrm{Kg}), \mathrm{IN}(0.2 \mathrm{mg} / \mathrm{Kg})$, or IN $(1.0 \mathrm{mg} / \mathrm{Kg})$ on days 1,2 and 3 postnatal age. At P14, the pups were sacrificed and retinal mRNA expression of VEGF188, VEGF164, VEGF120, VEGFR1, VEGFR2, Npn1, Npn2 and PEDF were examined.

Results: Transcripts for VEGF164 were more abundant in the rat retina than VEGF188 and VEGF164 transcripts were decreased with $50 \mathrm{mg}$ IB ( $<<0.05$ vs Sal), and both doses of IN $(\mathrm{p}<0.01$ vs Sal). VEGF120 was suppressed only with $50 \mathrm{mg} \mathrm{IB}$ ( $\mathrm{p}<0.01$ vs Sal). Transcripts for Npn1 and $\mathrm{Npn} 2$ were co-expressed and abundant in the retina. Npn1 mRNA remained unchanged but Npn2 mRNA was significantly increased with $1.0 \mathrm{mg}$ IN ( $<<0.01$ vs Sal). IB and IN had no significan effects on retinal VEGFR1 or PEDF mRNA expression.

Conclusions: Abundant expression of $\mathrm{Npn} 1$ and $\mathrm{Npn} 2$ in the retina suggests their involvement in retinal development. Although IN suppressed retinal VEGF164 transcripts, it had no effect on VEGFR1 and VEGFR2. In contrast, the high dose of IB suppressed VEGF164, VEGF120, and VEGFR2. IB appears to be more effective than IN for suppression of retinal VEGF signaling in rats, suggesting a possible novel therapy for retinal neovascularization.
Background/Aims: VEGF is an angiogenic factor involved in retinal development through interVEGF120. While no differences in VEGF188 mRNA expression were detected among the groups, 